\title{
Prevalence of fibromyalgia in premenopausal and postmenopausal women and its relation to climacteric symptoms
}

\author{
Sebastián Carranza-Lira, Idun Berenice Villalobos Hernandez
}

Instituto Mexicano del Seguro Social, México

\begin{abstract}
Aim of the study: To compare fibromyalgia prevalence in premenopausal and postmenopausal women and its relation to the climacteric symptoms.

Material and methods: Two hundred and nine women were studied, who attended the gynecology consultation at the hospital. They were divided in two groups: group I (premenopausal, $n=113$ ) and group II (postmenopausal, $n=96$ ). In all of them, climacteric symptoms and fibromyalgia diagnostic criteria were investigated; for the latter, the evaluations were done according to the 1990 and 2010 criteria of the American College of Rheumatology.

Results: When groups I and II were compared, no differences were found in somatometry, medicament consumption and associated diseases. When analyzing the general group, the fibromyalgia prevalence was greater in the postmenopausal women. However, when comparing the groups according to climacteric symptoms, in group I, $29 \%$ of symptomatic women had fibromyalgia, while only $4 \%$ of asymptomatic ones $(p<0.002)$. In group II, $15.7 \%$ of symptomatic women, and $2.5 \%$ of asymptomatic ones had fibromyalgia $(p<0.02)$. In group I, the more common painful points were the lower back (45.5\%), neck (35.7\%), and upper back (32.1\%). The more frequent symptoms were non-restful sleep ( $49 \%)$, followed by fatigue and cognitive symptoms ( $42 \%$ for each one). In group II, the more common painful points were the lower back (42\%), neck (40\%) and upper back (38.5\%). The more frequent symptoms were fatigue (69.6\%), cognitive symptoms (59.3\%) and non-restful sleep (57\%).

Conclusions: In premenopausal women, fibromyalgia was related to the presence of climacteric symptoms and in postmenopausal women - to their absence.
\end{abstract}

Key words: fibromyalgia, climacteric, symptoms.

\section{Introduction}

Fibromyalgia (FM) is a common syndrome, which affects approximately $2 \%$ of the world population, and $80-90 \%$ of them are women between 30 and 50 years of age [1].

The etiology of FM is unknown, however the most accepted hypothesis is the abnormality in pain perception at the brain level; it is impossible to specify if this is an exaggerated reaction to a normal stimulus or an exaggerated response to painful stimuli [2, 3].

The main symptoms are generalized pain and abnormal rigidity, though others, such as as fatigue, bad quality of sleep, difficulty to concentrate and emotional stress are also common [4].

Fibromyalgia patients have been found to show low neurotransmitter levels, such as serotonin and encephalin. Also, a probable alteration in the hypothalamus-hypophysis-adrenal axis has been proposed, as sometimes FM begins to develop after stressful situations [3].
Fibromyalgia diagnosis is mainly clinical and is done according to the 1990 [5] and 2010 [6, 7] American College of Rheumatology (ACR) criteria.

The climacterium is a part of women's ageing process, and is related to a decrease in estrogen levels. During this period, several symptoms are present such as vasomotor, somatic (myalgia, arthralgia and fatigue) as well as psychical ones (melancholia, emotional instability and asthenia) [8], which (excluding the vasomotor symptoms) can be confused with those of fibromyalgia.

The FM and climacterium chronologically co-exist, but there is no evidence to state that the decrease in sexual hormones can be responsible for the clinical features.

However, due to the association and similitude between the climacteric symptoms and those of FM, the objective of this study was to compare the prevalence of FM before and after the menopause and analyze its relation with the climacteric symptoms. 


\section{Material and methods}

Two hundred and nine women, 30 to 60 years of age, seen at the gynecology consultation at the hospital in 2012 and 2013 were studied. In all of them, weight $(\mathrm{kg})$, height $(\mathrm{m})$, waist and hip perimeters $(\mathrm{cm})$ were measured. The body mass index (BMI, weight/height ${ }^{2}$ ) as well as the waist-to-hip ratio (WHR, waist perimeter/hip perimeter) were calculated. Women were divided according to their menopausal status in group I - premenopausal and group II - postmenopausal (12 months or more since the last menstrual period). In all of them, climacteric symptoms and FM presence were investigated using (for the latter group) the proposed 1990 and 2010 ACR criteria.

According to the 1990 criteria, patients must have the following:

a) generalized pain for at least three months,

b) pain to palpation in at least 11 of the 18 selected points.

According to the 2010 criteria [5-7], they were considered to have FM if the following conditions were met:

a) generalized pain index $>7$ and a severity of symptoms score $>5$, or, generalized pain index between 3 and 6 and severity of symptoms score $>9$,

b) when symptoms were present in the same place for at least three months,

c) the patient does not have another condition that can explain the pain.

Definitions:

1. Generalized pain index: Number of areas, in which the patient had pain during the last week (score from 0 to 19).

2. Evaluated areas: the shoulder, hip (gluteus and trochanter), arm, forearm, thigh, leg (right or left), jaw, neck, thorax, abdomen, upper back and lower back.

3. Severity of symptoms score:

- fatigue,

- non-restful sleep,

- cognitive symptoms.

For any of these 3 symptoms, the grade of intensity during the previous week is indicated according to the following scale: 0 = without problem: no major fatigue due to usual, restful sleep and no cognitive problems (memory loss, etc.), 1 = mild: the patient has the above symptoms - mild or intermittent, 2 = moderate: the problem is considerable and presents frequently and/ or at moderate intensity, 3 = severe: continuous symptoms, with social problems conditioned by these alterations.

After evaluating these symptoms, it is decided if the patient has: 0 = no symptoms, 1 = few symptoms, 2 = moderate symptoms or 3 = severe symptoms.

The sum of the severity of each one of them, plus the extension of the severity of them gives a score between 0 and 12 .
Associated diseases, such as irritable bowel syndrome, temporomandibular joint dysfunction, frequent and long headaches, as well as the use of medicaments that can confound the FM clinical findings or suggest the presence of chronic pain (steroid and non-steroid antiinflammatory drugs and anti-depressants) were also investigated. In addition, physical activity was investigated, considering as positive if the woman had been regularly doing exercise for more than six months (more than three times per week and for more than 30 minutes each day).

Climacteric symptoms were investigated by asking all women independently about their age, if they had vasomotor (hot flushes, night sweats), somatic (headache, general discomfort) and psychical symptoms (mood changes, irritability) and for how long they had them. Also the time since menopause, if applicable, was investigated. Excluded from the study were women with chronic diseases, who had been either hysterectomized or oophorectomized, with the actual use of hormone therapy or hormonal contraception, as well as with the presence of any degenerative osteoarticular disease.

The sample size was calculated considering $90 \%$ confidence level, $80 \%$ power of the test, the frequency of presentation of FM in the general population of $3 \%$ and $10 \%$ in postmenopausal women, resulting in $n=96$ women per group.

To compare the two groups, Student $t$-test was used for continuous variables and percentual values were analyzed with $\chi^{2}$ test.

The protocol was authorized by the Local Committee of Research and Ethics in Research (number R-20123606-10). All women gave their consent to participate and signed the consent forms.

\section{Results}

Two hundred and nine women were studied and divided in two groups, group I - premenopausal women $(n=113)$ and group II - postmenopausal women $(n=96)$.

Their age was $42.1 \pm 5.3$ years and $54.1 \pm 4.6$ years, for group I and II, respectively $(p<0.001)$. No statistically significant differences were found in weight, height, $\mathrm{BMI}$, waist perimeter, hip perimeter and WHR between the groups (Table I).

The presence of associated diseases (irritable bowel syndrome, back pain and chronic headache), as well as physical activity, did not show any statistically significant difference between the groups.

The proportion of women with vasomotor symptoms was $12.4 \%$ vs. $47.0 \%$ ( $p<0.001$ ), with somatic symptoms: $11.5 \%$ vs. $26.0 \%(p<0.006)$ and with psychical symptoms: $14.1 \%$ vs. $51.0 \%(p<0.001)$, for groups I and II, respectively.

According to the 2010 ACR criteria, in group I, 7.9\% had FM and in group II, 10.4\%. According to the 1990 ACR criteria, no one from group I and $3.1 \%$ from group II had FM. 
Tab. I. Clinical characteristics in women according to the menopausal status

\begin{tabular}{lccc}
\hline Factors & Premenopausal & Postmenopausal & $p$ \\
\hline Age (years) & $42.1 \pm 5.3$ & $54.1 \pm 4.6$ & $<0.001$ \\
\hline Weight $(\mathrm{kg})$ & $68.8 \pm 13.1$ & $69.2 \pm 11.8$ & $\mathrm{NS}$ \\
\hline Height $(\mathrm{m})$ & $1.56 \pm 0.07$ & $1.55 \pm 0.07$ & $\mathrm{NS}$ \\
\hline BMI $\left(\mathrm{kg} / \mathrm{m}^{2}\right)$ & $28.3 \pm 4.8$ & $28.9 \pm 4.6$ & $\mathrm{NS}$ \\
\hline Waist $(\mathrm{cm})$ & $96.0 \pm 12.6$ & $96.3 \pm 11.0$ & $\mathrm{NS}$ \\
\hline Hip $(\mathrm{cm})$ & $105.8 \pm 10.8$ & $106.2 \pm 11.0$ & $\mathrm{NS}$ \\
\hline WHR & $0.91 \pm 0.06$ & $0.91 \pm 0.04$ & $\mathrm{NS}$ \\
\hline BMI - body mass index, WHR - waist-hip ratio &
\end{tabular}

After analyzing the FM diagnostic criteria, these were significantly greater in group II (Table II).

In the whole study group, without division according to the menopausal status, patients with vasomotor, somatic and psychical symptoms had a greater generalized pain index, severity of symptoms score and positive pain points (Table III).

After dividing each group according to the presence or absence of climacteric symptoms, in group I, $17(15 \%)$ out of 113 women, had climacteric symptoms and 96 (85\%) were asymptomatic; from symptomatic ones, 5 (29\%) had FM according to 2010 ACR criteria. Of the 96 asymptomatic premenopausal women, 4 (4\%) had FM according to the same criteria $(p<0.002)$. In group II, 57 (59.4\%) out of 96 women had climacteric symptoms and $9(15.7 \%)$ had FM, of the $39(40.6 \%)$ asymptomatic ones, $1(2.5 \%)$ had FM $(p<0.02)$.

After comparing separately the diagnostic criteria (generalized pain index, severity of symptoms score and positive painful points at exam), it was found that the generalized pain index and painful points were greater in premenopausal women with climacteric symptoms. Similarly, the generalized pain index, severity of symptoms score and positive painful points at physical exam were greater in premenopausal women with somatic and psychical symptoms (Table IV).

In group II, the severity of symptoms score was statistically significantly higher in women with vasomotor and somatic symptoms. In women with psychical
Tab. II. Fibromyalgia diagnostic criteria

\begin{tabular}{lccc}
\hline & Premenopausal & Postmenopausal & $p$ \\
\hline $\begin{array}{l}\text { Generalized } \\
\text { pain index }\end{array}$ & $3.4 \pm 3.2$ & $4.3 \pm 3.5$ & $<0.040$ \\
\hline $\begin{array}{l}\text { Severity of } \\
\text { symptoms } \\
\text { score* }\end{array}$ & $2.3 \pm 2.2$ & $3.0 \pm 2.2$ & $<0.016$ \\
\hline $\begin{array}{l}\text { Positive pain- } \\
\text { ful points }\end{array}$ & $1.7 \pm 2.2$ & $2.9 \pm 2.9$ & $<0.001$ \\
\hline${ }^{*}-2010$ criteria, $^{* *}-1990$ criteria & &
\end{tabular}

symptoms, the generalized pain index and severity of symptoms score were greater than in asymptomatic women (Table IV). Other indexes did not have any statistically significant difference.

When comparing the painful sites referred during the interview, as part of the 2010 criteria, a non-significant greater difference was found in presentation in most of the sites in postmenopausal women, with the exception of the upper back, lower back and abdomen.

Likewise, in group II, the severity of symptoms score had higher positivity percentages with fatigue being the most frequent symptom.

Physical exam revealed that positive painful points according to 1990 ACR criteria were more prevalent in postmenopausal women.

In women with climacteric symptoms, there was a greater presence of referred pain and induced pain at exam than in asymptomatic ones. Fatigue, non-restful sleep and cognitive symptoms in total percentage were also greater in symptomatic women.

When premenopausal and postmenopausal women with climacteric symptoms were compared, it was found that premenopausal ones had a greater presentation of diagnostic criteria for FM in all the analyzed indexes (Table IV).

When analyzing pre- and postmenopausal women without climacteric symptoms, postmenopausal women showed a higher frequency of painful points, fatigue, non-restful sleep and cognitive symptoms (Table IV). In

Tab. III. Fibromyalgia diagnostic criteria qualification, according to climacteric symptoms

\begin{tabular}{|c|c|c|c|c|c|c|}
\hline \multirow{2}{*}{ Symptoms } & \multicolumn{2}{|c|}{ Vasomotor } & \multicolumn{2}{|c|}{ Somatic } & \multicolumn{2}{|c|}{ Psychical } \\
\hline & Present & Absent & Present & Absent & Present & Absent \\
\hline \multirow[t]{2}{*}{$\mathrm{GPI}^{*}$} & $5.2 \pm 4.2$ & $3.2 \pm 2.8$ & $6.3 \pm 4.3$ & $3.2 \pm 2.8$ & $5.6 \pm 4.1$ & $3.0 \pm 2.6$ \\
\hline & \multicolumn{2}{|c|}{$p<0.001$} & \multicolumn{2}{|c|}{$p<0.000$} & \multicolumn{2}{|c|}{$p<0.000$} \\
\hline \multirow[t]{2}{*}{$\mathrm{SSS}^{*}$} & $3.5 \pm 2.2$ & $2.3 \pm 2.2$ & $3.8 \pm 2.1$ & $2.4 \pm 2.2$ & $3.7 \pm 2.3$ & $2.1 \pm 2.0$ \\
\hline & \multicolumn{2}{|c|}{$p<0.001$} & \multicolumn{2}{|c|}{$p<0.000$} & \multicolumn{2}{|c|}{$p<0.000$} \\
\hline \multirow[t]{2}{*}{$P P P^{* *}$} & $3.1 \pm 3.4$ & $1.9 \pm 2.2$ & $3.3 \pm 3.6$ & $2.0 \pm 2.3$ & $3.3 \pm 3.4$ & $1.8 \pm 2.1$ \\
\hline & \multicolumn{2}{|c|}{$p<0.02$} & \multicolumn{2}{|c|}{$p<0.05$} & \multicolumn{2}{|c|}{$p<0.002$} \\
\hline
\end{tabular}

$\mathrm{GPI}$ - generalized pain index, SSS - severity of symptoms score, PPP - positive painful points

* -2010 criteria, ${ }^{* *}-1990$ criteria 
Tab. IV. Fibromyalgia diagnostic criteria score according to symptom presence and menopausal status

\begin{tabular}{|c|c|c|c|c|c|c|c|}
\hline \multicolumn{2}{|c|}{ Symptoms } & \multicolumn{2}{|c|}{ Vasomotor } & \multicolumn{2}{|c|}{ Somatic } & \multicolumn{2}{|c|}{ Psychical } \\
\hline & & Pre & Post & Pre & Post & Pre & Post \\
\hline \multirow[t]{3}{*}{ Present } & $\mathrm{GPI}^{*}$ & $\begin{array}{c}6.7 \pm 4.3 \\
\text { a-a } p<0.006\end{array}$ & $4.8 \pm 4.0$ & $\begin{array}{c}7.8 \pm 3.6 \\
\text { d-d } p<0.000\end{array}$ & $5.5 \pm 4.4$ & $\begin{array}{c}6.7 \pm 4.1 \\
h-h \quad p<0.002\end{array}$ & $\begin{array}{r}5.2 \pm 4.0 \\
k-k p<0.007\end{array}$ \\
\hline & $\mathrm{SSS}^{*}$ & $3.1 \pm 2.2$ & $\begin{array}{c}3.6 \pm 2.2 \\
c-c p<0.02\end{array}$ & $\begin{array}{c}3.9 \pm 2.5 \\
\text { e-e } p<0.005\end{array}$ & $\begin{array}{c}3.8 \pm 1.9 \\
\mathrm{~g} g \mathrm{~g} p<0.05\end{array}$ & $\begin{array}{c}3.4 \pm 2.4 \\
{ }_{i-i} p<0.02 \\
\end{array}$ & $\begin{array}{c}3.8 \pm 2.2 \\
{ }^{1-1} p<0.000\end{array}$ \\
\hline & $\mathrm{PPP}^{\star * *}$ & $\begin{array}{c}3.3 \pm 3.0 \\
\text { b-b } p<0.004\end{array}$ & $3.1 \pm 3.6$ & 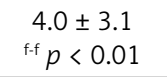 & $3.0 \pm 4.0$ & $\begin{array}{c}3.4 \pm 3.1 \\
j-j p<0.02\end{array}$ & $3.2 \pm 3.5$ \\
\hline \multirow[t]{6}{*}{ Absent } & $\mathrm{GPI}^{*}$ & $2.8 \pm 2.8^{a-a}$ & $3.9 \pm 2.8$ & $2.8 \pm 2.7^{\mathrm{d}-\mathrm{d}}$ & $3.9 \pm 3.0$ & $2.8 \pm 2.7^{h-h}$ & $3.4 \pm 2.4^{k-k}$ \\
\hline & & \multicolumn{2}{|c|}{$p<0.03$} & \multicolumn{2}{|c|}{$p<0.009$} & & \\
\hline & \multirow[t]{2}{*}{$\mathrm{SSS}^{*}$} & $2.6 \pm 2.2$ & $2.5 \pm 2.1^{c-c}$ & $2.1 \pm 2.1$ e-e & $2.8 \pm 2.2^{\mathrm{g} g}$ & $2.1 \pm 2.2^{\mathrm{i}-\mathrm{i}}$ & $2.2 \pm 1.8^{1-1}$ \\
\hline & & \multicolumn{6}{|c|}{$p<0.04$} \\
\hline & \multirow[t]{2}{*}{$\mathrm{PPP}^{* *}$} & $1.5 \pm 2.0^{b}$ & $2.8 \pm 2.2$ & $1.4 \pm 1.9^{f-f}$ & $2.9 \pm 2.5$ & $1.4 \pm 1.9^{\mathrm{j}-\mathrm{j}}$ & $2.7 \pm 2.1$ \\
\hline & & \multicolumn{2}{|c|}{$p<0.000$} & \multicolumn{2}{|c|}{$p<0.000$} & \multicolumn{2}{|c|}{$p<0.001$} \\
\hline
\end{tabular}

the whole group analysis, without dividing by the menopausal status, the generalized pain index, symptoms severity score and positive painful points at physical exam, were significantly greater in women with climacteric symptoms.

When dividing by the menopausal status, in postmenopausal women without vasomotor symptoms, the generalized pain index at physical exam was significantly greater. Similarly, in postmenopausal women without somatic symptoms, the generalized pain index, severity of symptoms score, and positive painful points were significantly greater and in women without psychical symptoms, the positive painful points at physical exam were greater in the postmenopausal ones. Different sites were referred depending on whether women were in the premenopause or postmenopause and if they were symptomatic or not, being more frequent in symptomatic premenopausal ones and in the asymptomatic postmenopausal.

In group I, the more common painful points were the lower back (45.5\%), neck (35.7\%), upper back (32.1\%) and abdomen (24.1\%). When analyzing the more frequent symptoms, non-restful sleep was the most frequent one (49\%), followed by fatigue and cognitive symptoms (42\% for each one). In physical exam the most frequent painful point was the supraspinous (22.3\%) followed by the trapezium (14.3\%), the occipital (13.4\%) and the inter-rib (12.5\%), being more commonly bilateral.

In group II, the more common painful points were the lower back (42\%), neck (40\%), upper back (38.5\%) and right leg (36.5\%). The more frequent symptoms were fatigue $(69.6 \%)$ followed by cognitive symptoms (59.3\%) and non-restful sleep (57\%). At physical exam, the more common painful points were trapezium (25\%), supraspinous (24\%), inter-rib (22.9\%) and gluteus (20.8\%).

\section{Discussion}

In this study it was found that in pre- and postmenopausal women without climacteric symptoms, the postmenopausal women showed a higher frequency of painful points, fatigue, non-restful sleep and cognitive symptoms. In the whole group analysis, without dividing by the menopausal status, the generalized pain index, symptoms severity score and positive painful points at physical exam, were significantly greater in women with climacteric symptoms.

Other analyzed parameters such as age, BMI, WHR and associated diseases considered in the group of central sensitivity syndromes were not statistically significantly different.

Also it has been reported that symptoms ameliorate and a lower percent of FM exist in women who do exercise [9], but it was not possible to reach a conclusion about exercise since most of the study patients were sedentary.

A study indicates that FM symptoms are more intense after the beginning of menopause and are related to hormone changes such as changes occurring during the menstrual cycle [10], but without distinction if postmenopausal women had climacteric symptoms. However, others indicate that a higher proportion of FM cases are found in women with climacteric symptoms [11]. And peri- and postmenopausal women with fibromyalgia and chronic fatigue symptoms had greater vasomotor symptoms scores [12], both findings being similar to our results.

Due to the similarity between the FM and climacteric symptoms, the question is whether FM symptoms are a part of climacteric symptoms or vice versa; this might be useful to know because the prognosis, study and treatment would be different. 
If these two entities are nosologically different, the decrease in estrogen levels can only be a risk factor for the developing FM as has already been proposed [13].

The results of our study demonstrate that the positivity of FM symptoms is more related to climacteric symptoms than to the menopausal status, since when comparing pre- and postmenopausal women, premenopausal ones had more painful sites than postmenopausal ones, so FM is more frequent in the premenopause when climacteric symptoms exist and estrogen levels continue to be acceptable.

This study has a limitation of not correlating the symptoms with estradiol levels but this is needed to detect the effect of estrogen on FM.

\section{Conclusions}

Fibromyalgia was more common in premenopausal women with climacteric symptoms than in postmenopausal ones without them.

\section{Acknowledgement}

Acknowledgement to Mr. Vasiliy Krivtsov for the review and editing of the manuscript's grammar, spelling and syntax.

\section{Disclosure}

Authors report no conflicts of interest.

\section{References}

1. Leza JC. Fibromialgia: un reto también para la neurociencia. Rev Neurol 2003; 36: 1165-1175.

2. Guymer EK, Littlejohn GO. Fibromyalgia. Diagnosis and management. ACO 2002; 10: 81-84.

3. Villanueva VL, Valía JC, Cerda C, et al. Fibromialgia: diagnóstico y tratamiento. El estado de la cuestión. Rev Soc Esp Dolor 2004; 11: 430-443.

4. Neyro JL, Franco R, Rodríguez E, et al. Fibromialgia y climaterio: Asociación o coincidencia? Ginecol Obstet Mex 2011; 79: 572-578.

5. Goldenberg DL. Diagnosis and differential diagnosis of fibromyalgia. Am J Med 2009; 122: S14-S21.

6. Wolfe F, Häuser W. Fibromyalgia diagnosis and diagnostic criteria. Ann Med 2011; 43: 495-502.

7. Arnold LM, Clauw DJ, McCarberg BH. Improving the recognition and diagnosis of fibromyalgia. Mayo Clin Proc 2011; 86: 457-464.

8. Carranza LS. Climaterio. In: Introducción a la endocrinología ginecológica. Trillas, México 2011; 121-134.

9. Sañudo B, Galliano D, Carrasco L, et al. Aerobic exercise versus combined exercise therapy in women with fibromyalgia syndrome: A randomized controlled trial. Arch Phys Med Rehabil 2010; 91: 1838-1843.

10. Pamuk ON, Cakir N. The variation in chronic widespread pain and other symptoms in fibromyalgia patients. The effects of menses and menopause. Clin Exp Rheumatol 2005; 23: 778-782.

11. Blümel JE, Palacios S, Legorreta D, et al. Is fibromyalgia part of the climacteric syndrome? Maturitas 2012; 73: 87-93.

12. Wilbur J, Shaver J, Kogan J, et al. Menopausal transition symptoms in midlife women living with fibromyalgia and chronic fatigue. Health Care Women Int 2006; 27: 600-614.

13. Waxman J, Zatzkis SM. Fibromyalgia and menopause. Examinationof the relationship. Postgrad Med 1986; 80: 165-167. 